\title{
FRACTIONAL DIFFERENCE INEQUALITIES OF OPIAL TYPE AND INITIAL VALUE PROBLEM
}

\section{G. V. S. R. DEEKShitulu AND J. JAGAN MOHAN}

Abstract. In this paper some discrete Opial type inequalities of fractional order are established and using these inequalities of Opial type, a bound to the solution of a fractional initial value problem is obtained.

Mathematics subject classification (2010): 39A10, 39A99.

Keywords and phrases: Difference equations, fractional order, inequalities, initial value problem.

\section{REFERENCES}

[1] Atsushi Nagai, Fractional logistic map, 2002.

[2] P. R. BEESACK, On certain discrete inequalities involving partial sums, Canad. J. Math. 21 (1969), 222-234.

[3] G. V. S. R. Deekshitulu and J. Jagan Mohan, Fractional difference inequalities, Communications in Applied Analysis 14, 1 (2010), 89-98.

[4] G. V. S. R. DeEkshitulu AND J. JaGAn Mohan, Fractional difference inequalities of Bihari type, Communications in Applied Analysis 14, 4 (2010), 343-354.

[5] J. B. Diaz And T. J. Osler, Differences of fractional order, Math. Comp. 28 (1974), 185-201.

[6] K. FAN, O. TAUSSKY AND J. TODD, Discrete analogues of inequalities of Wirtinger, Monatsh. Math. 59 (1955), 73-90.

[7] Henry L. Gray and Nien fan Zhang, On a New Definition of the Fractional Difference, Math.Comp. 50 (1988), 513-529.

[8] R. HiRota, Lectures on difference equations, Science-sha, 2000 (in Japanese).

[9] A. Lasota, A discrete boundary value problem, Ann. Polon. Math. 20 (1968), 183-190.

[10] V. Lakshmikantham and S. Leela, Differential and integral inequalities, Vol. I, Academic Press, New York, 1969.

[11] V. Lakshmikantham And D. Trigiante, Theory of difference equations, Academic Press, New York, 1988.

[12] C. M. LEE, On a discrete analogue of inequalities of Opial and Yang, Canad. Math. Bull. 11 (1968), $73-77$.

[13] B. G. PACHPATTE, Integral and finite difference inequalities and applications, Elsevier, The Netherlands, 2006.

[14] I. Podlubny, Fractional differential equations, Academic Press, San Diego, 1999.

[15] Ravi P. Agarwal and Peter Y. H. PAng, Opial inequalities with applications in differential and difference equations, Vol. 320, Kluwer Academic Publishers, London, 1995.

[16] J. S. W. Wong, A discrete analogue of Opial's inequality, Canad. Math. Bull. 10 (1967), 115-118. 